\title{
0895: Insect resistance to Bt toxins in Brazil and Latin America
}

\author{
Monday, September 26, 2016 \\ 02:15 PM - 02:30 PM \\ $\bigcirc$ Convention Center - Room W230 D
}

Introduction: In Latin America, cultivation of transgenic crops during 2014/2015, reached 74 million hectares, almost half of the global GM-planted area. Brazil is the largest country cultivating transgenic plants in Latin America, accounting for $57 \%$ of planted acreage. The second largest is Argentina, with 24.4 million hectares, followed by Paraguay, Uruguay, Bolivia, Mexico and Colombia. To date, insect resistance to Bt crops has been reported in Puerto Rico and Brazil. In Puerto Rico, resistance was detected in Spodoptera frugiperda on Bt-corn expressing Cry1F protein. In Brazil, populations of $S$. frugiperda were resistant to the same toxin, and cross-resistance to Cry $1 A a$, Cry $1 \mathrm{Ab}$ and Cry1 Ac toxins (present in other transgenic events used in Brazil) was also seen, but cross-resistance to Cry2Aa and Cry2Ab toxins has not been identified.

Methods: Methods included binding competition assays, enzymatic activities and gene expression analysis.

Results/Conclusion: Heterologous competition assays among Cry1F and Cry $1 \mathrm{~A}$ toxins showed that they share binding sites, and therefore it is not recommended to use pyramided plants with these toxins to control $S$. frugiperda or to use other genetically modified crops expressing these proteins in the same agricultural setting. Data from different $S$. frugiperda populations collected at different fields related to their aminopetidase- $\mathrm{N}$, alkaline phosphatase and cadherin activities will be presented. In face of this scenario, it is important that all involved agents (companies, extension services, farmers, scientific community and governments) of GM-producing countries unite their efforts to establish guidelines that will enable greater durability of $\mathrm{Bt}$ technologies, either as bioinsecticides or as Bt crops.

doi: $10.1603 /$ ICE.2016.93642

\section{Author}

Rose Monnerat

Embrapa Recursos Genéticos e Biotecnología

\section{View Related Events}

Symposium: 175 Symposium: Bt Mode of Action, Resistance Mechanisms, and Global Patterns

Program: Symposium

Day: Monday, September 26, 2016 